\title{
Prospective in Social Sciences
}

\author{
Sandro Serpa \\ University of the Azores, Faculty of Social and Human Sciences, Department of Sociology; \\ Interdisciplinary Centre of Social Sciences - CICS.UAc/CICS.NOVA.UAc; \\ Interdisciplinary Centre for Childhood and Adolescence - NICA - UAc
}

\begin{abstract}
The capacity to forecast events is one of the characteristics sought by so-called exact sciences. In the social sciences such regularity, although often sought after, cannot be achieved in such a precise way, and there is sometimes the temptation to prophesy and not to predict in a substantiated way, assuming a certain unpredictability in the probabilistic sense inherent to social phenomena. This communication seeks to problematize and discuss the relationship between social sciences, especially sociology but also economics and education. It can be seen that: 1 . the social sciences, by the characteristics of their object of study - the facts and social situations -, deal with tendencies; 2 . personal ideology can influence the attempt to anticipate the future; 3 . the dissemination of information from the social sciences, itself, has the potential to modify reality and consequently put into question its capacity for social foresight. These conclusions do not draw merit from the social sciences, having as implication the need to be aware of these characteristics in the social scientific approach.
\end{abstract}

Keywords: future anticipation studies; prophetism; social change; social prevision; social sciences. 